\title{
Fiber Degradation in Buffalo - An Innovative Approach
}

\author{
${ }^{1}$ S.K. Jadhav, ${ }^{2}$ G.B. Deshmukh, ${ }^{3}$ S. Sathapathy, ${ }^{4}$ S.R. Lende, ${ }^{5}$ G.G. Sewatkar, \\ ${ }^{6}$ S.K.Joshi \\ Department of Animal Nutrition, Nagpur Veterinary College, Nagpur-440006 (M.S.) India
}

\begin{abstract}
The ruminant animals may be considered as the foundation of animal agriculture because they served mankind all the way through many millennia. They are best adapted to utilize the fibrous feed components. Lignocellulose will therefore always be important in ruminant diets, and even in intensive systems is incorporated into the ration because it is both economical and necessary for normal healthy rumen function. Improvement in the ability of the rumen microbiota to degrade plant cell wall is generally highly desirable and usually leads to improved animal performance. The symbiosis between animal and microbe in the rumen allows for a cooperative system in which both the host and animal derive a benefit. The rumen is a capacious pregastric fermentation chamber that sustains a rich community of microorganisms that rapidly colonize and digest feed particles. The end products of this fermentation are fatty acids, which form a major metabolic fuel for the ruminant and microbial cells that are a major source of protein and amino acids when absorbed in the lower digestive tract of the animal. Tropical buffaloes can grow properly with low quality roughage, agricultural and industrial waste with basic structure high lignocellulose as main energy source. On the other hand, conversion of feed crude fiber to animal product was not optimum in intensive animal farming (especially dairy cattle and buffaloes). Only 15-45\% energy from crude fiber can be used, while 20-70\% undigested cellulose were carried out with faeces. This is because the ruminal digestion of plant cell walls are not complete.
\end{abstract}

Keywords :- Fiber degradation, Buffalo calves, rumen metabolites

\section{Introduction}

The ruminant animals may be considered as the foundation of animal agriculture because they served mankind all the way through many millennia. The ruminant production systems are dependent worldwide on forage as the main nutritional components. The microbial mode digestion allows ruminants to better unlock the unavailable energy in the plant cell wall components than other herbivores. This gives ruminant animals the ability to convert low nutritive and resistant lignocellulosic biomass to milk, meat, wool and hides. However, most forage plants are high in cell walls and low in nitrogen $(\mathrm{N})$ and energy content. Despite the importance of fibrous components in forage for salivation, rumen buffering and efficient production of ruminal end products, only 10 to $35 \%$ of energy intake is available as net energy. This is because the ruminal digestion of plant cell walls is not complete. Most available C4 grass pasture and crop residues are of poor nutritive value as they consists of highly lignified stems during the dry seasons. Consequently, performance of ruminants fed such feedstuffs as major components of nourishment is often suboptimal because of their high lignin concentrations. When insufficient coarse fibrous diet with high grain or less forage is fed, the rumen $\mathrm{pH}$ falls and efficiency of digestion is compromised. This is because of the accumulation of organic acids (VFAs and lactic acid) and reduction of buffering capacity of the rumen. For that reason, an accurate daily fibre content will therefore prevent any economical loss from digestive and metaboilc disorders leading sometimes to death.

\section{A) Chemistry And Structure Of Plant Cell Walls}

Plant cells contain primary cell walls and some grow thick cell wall layers within the primary wall. The primary growth consists of the elongation of cell walls within chemical fractions such as polysaccarides (Cellulose, xylans, pectins), protein matrix and phenolic acids (ferulic acids) are deposited. During the thickening of the secondary wall, compounds such as xylan, pectin and ferulic acids are less deposited in the wall in favours of lignocellulosic components. As plant tissues grow, lignin encrusts the cellulose microfibril and hemicellulose. This affects the structure of hemicellulose because of its high concentration in the primary wall. The lignification transforms the overall plant cell walls in a structured and rigid barrier to prevent any physical and biochemical damages within the plant. 


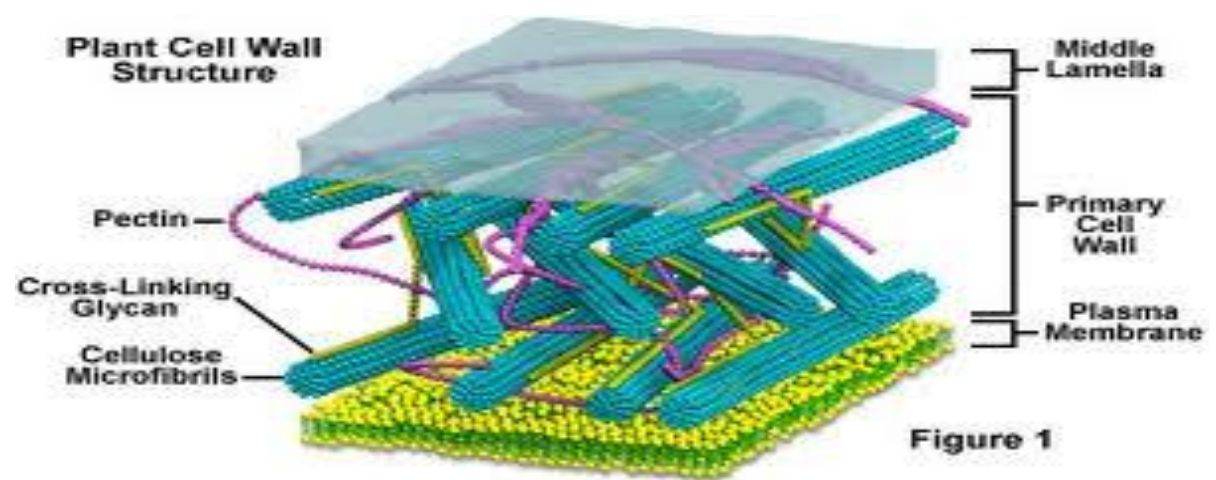

Fig. 1 Plant cell wall structure

\section{B) RUMEN MICROBIAL ECOSYSTEM}

The rumen contains large number of bacteria $-10^{10}-10^{11}$ cells $/ \mathrm{ml}$, protozoa $-10^{4}-10^{6} / \mathrm{ml}$ anaerobic fungi$10^{3}-10^{5} / \mathrm{ml}$ and bacteriophages $-10^{8}-10^{9}$ particles $/ \mathrm{ml}$.

\section{C) ROLE OF RUMEN MICROBES}

Bacteria - The bacteria attach with the feed particles with the help of glyco-protein coat and excrete fibre degrading enzymes and creates cavities on the feed particles. Protozoa - It engulf small fibrous feed particles by the process of phagocytosis. The protozoa do not have any intimate contact with the substrate, but they contribute a very significant portion of hydrolytic enzymes in the rumen contents. Fungi - The rumen fungi penetrate into the substrate and acts as a biological knife to cut the feed particle into several smaller pieces, thereby increasing total surface area of the feed on which either bacteria can act and hydrolysis or protozoa can engulf and hydrolyses into monosaccharides

\section{D) MOST COMMON RUMEN MICROBES}

Bacteria - Fibrobacter interstinalis, ruminococcus, clostridium etc. Protozoa - Eudiplodinium maggii, Epidinium ecaudatum caudatum, Ostracodinium etc. Fungi - Neocallimastix sp. and Orpinomyces.

\section{WHY BUFFALOES ARE EFFECTIVE FIBER DEGRADER THAN CATTLE ?}

The buffalo ruminal characteristics are being more favorable for utilization of NH3- $\mathrm{N}$ and have superior ability to handle stressful environment and adaption to a wider range of roughage sources. Total bacterial count is higher i.e. Cellulolytic bacteria -2 folds, Proteolytic and amylolytic bacteria - 5-7 folds, Fungi population- 1.5 folds and Enzymes activity -1.2 folds more in buffaloes than cattle (Wanapat et al ., 2001). The rumen of buffaloes is well adapted to utilize the ligno-cellulosic residue. It has been reported that when cattle and buffaloes were kept under similar condition , buffaloes utilized feeds more efficiently (about 2$3 \%)$ than cattle.

1) MODIFICATION OF FIBER BY EXOGENOUS MEANS

$\triangle$ PHYSICAL TREATMENTS- Soaking, Chaffing, Grinding, Pelleting, Steam under pressure, irradiation etc

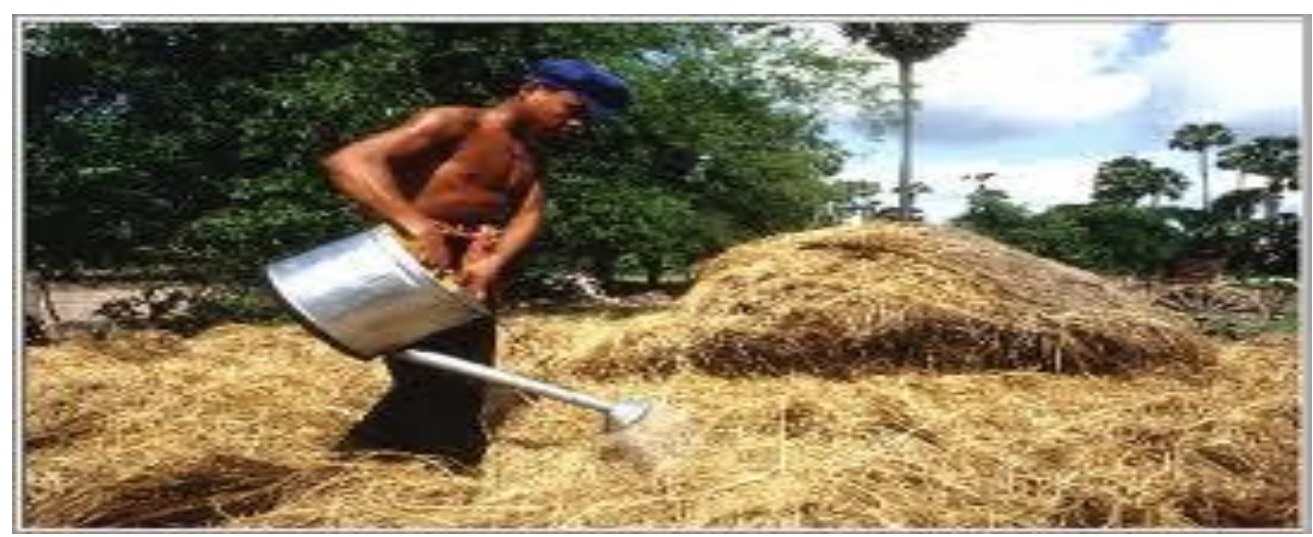

Fig.2 Urea treatment on straw 
$\triangle$ CHEMICAL TREATMENTS- - Alkali - $(\mathrm{NAOH}, \mathrm{KOH}, \mathrm{Ca}(\mathrm{OH}) 2, \mathrm{NH} 4 \mathrm{OH})$, Ammonia - (Gaseous , Aqueous, Urea-ammonia), Acids - ( $\mathrm{H} 2 \mathrm{SO} 4, \mathrm{HNO} 3$ )and salts - (Na2CO3, Nacl).

2) RUMEN INOCULATION OF ANAEROBIC FUNGI:- The inoculation of rumen microbes from wild herbivorus ruminants to ruminant animals that having more potential ability to degrade fiber. The fungi play an active and positive role in fibre degradation due to presence of different hydrolytic enzymes. The fibrebased diets stimulate the fungal growth in the rumen of buffalo in comparison to diets rich in easily fermentable carbohydrates. These fungi prefer to get attached to the most lignified tissues of plant feed material by producing variety of enzymes. It found that the digestibility straw is increased by 25 to $40 \%$ with use of different anaerobic fungi viz., Orpinomyces, Piromyces and Anaeromyces (Manikumar et al, 2002).
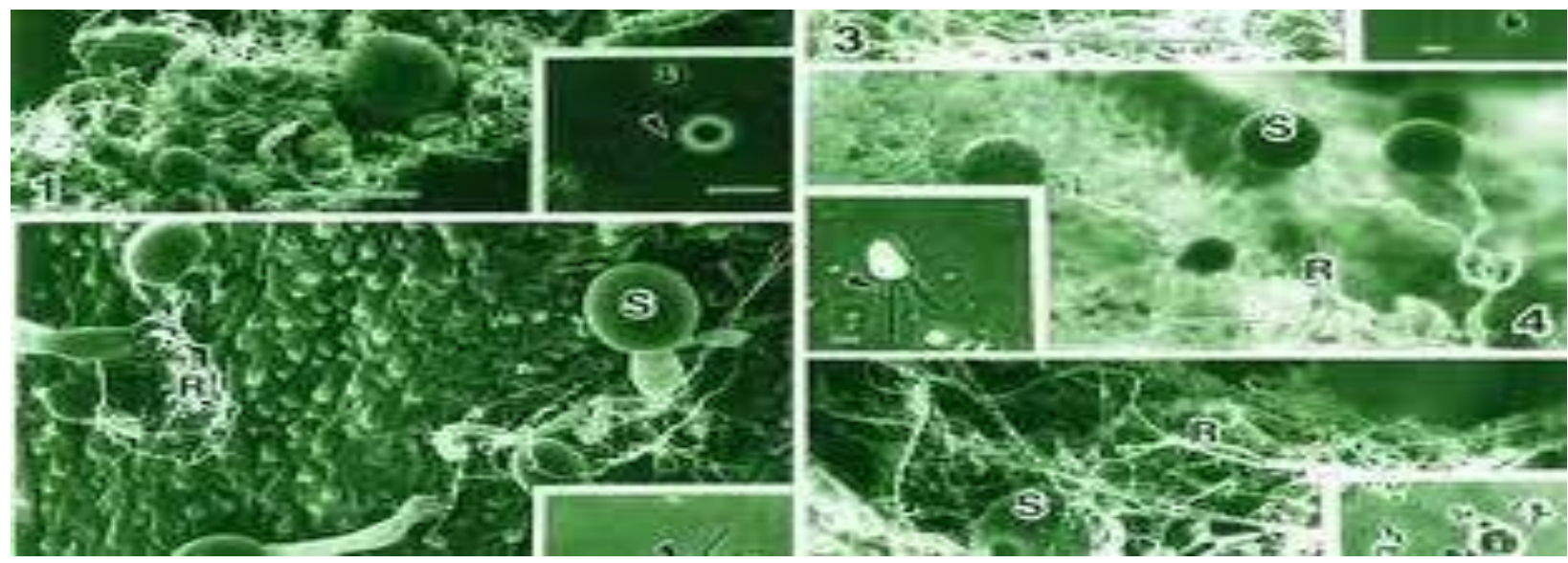

Fig. 3 Rumen anaerobic fungi

3) TRANS-INOCULATION OF RUMEN MICROBES :- It means inoculation of rumen microbes from one species to another species. Synergistes jonesii - A rumen microbes of goat species are able to degrade mimosine (Leucaena leucocephala) and its derivatives such as 3,4-DHP and 2,3-DHP. 3,4-DHP is a potent goitrogenic . The trans-inoculation of those goat rumen microbes to ruminants sensitive to mimosine toxicity resulted in the transfer of the capability of degrading DHP completely and efficiently.

4) USE OF FIBROLYTIC ENZYMES:- Fibrolytic enzymes (FE) have their potential to convert lignocellulose to glucose and other soluble sugars. They are of natural origin, non-toxic, non pathogenic and do not produce antibiotics. These enzymes consists of mainly cellulases, xylanases and other minor enzymes complexes, together they act to hydrolyse lignocellulosic materials. Objectives of using feed enzymes is to enhance availability of nutrients that are locked within cell wall components. For Ex. 1) Depol 40 is a mixture of enzymes from the fungi Aspergillus niger and Trichoderma spp. 2) Liquicell $\mathbf{2 5 0 0}$ is derived from Trichoderma reesei.

\section{Conclusion}

Fiber degradation efficiency is more in buffaloes than cattle and can be enhanced with rumen manipulation in ruminants. 